\title{
Cross-sectional analysis of physical activity in 2-4-year-olds in England with paediatric quality of life and family expenditure on physical activity
}

Laura Tinner ${ }^{1 *}$ (D), Ruth Kipping ${ }^{1}$, James White ${ }^{2}$, Russell Jago ${ }^{3,4}$, Chris Metcalfe ${ }^{1}$ and William Hollingworth ${ }^{1}$

\begin{abstract}
Background: Many children do not meet the recommended level of daily physical activity, even with the widely acknowledged health benefits associated with being physically active. There is a need to establish factors related to physical activity in children so that public health interventions may be appropriately designed. We investigated the association between Pediatric Quality of Life Inventory (PedsQL), family expenditure on physical activity and objectively measured daily physical activity in 2-4-year-old children.

Methods: Cross-sectional study with a sample of 81 UK preschool children taking part in the NAPSACC UK feasibility randomized controlled trial. Descriptive statistics are presented. We undertook Student t-tests to establish differences in physical activity by gender, age, parental education and nursery versus non-nursery days. Mixed effects linear regressions were used to model the association between minutes spent physically activity, minutes spent in moderate-to-vigorous (MVPA) physical activity and PedsQL scores (physical and psychosocial) and family expenditure on physical activity.

Results: Most children (88.9\%) did not engage in the recommended 180 min daily physical activity. There was mean (SD) of 141.9 (33.1) daily minutes of physically activity and 22.2 min per day $(S D=9.9)$ of MVPA. Boys and older children were more physically active. Children were more active on nursery days. There was no difference in physical activity by parental education. Half of the sample parents (50.6\%) spent less than $£ 9.00$ weekly on their pre-schooler's physical activity. Children within the highest tertile of PedsQL physical functioning scores had higher levels of MVPA (3.6, 95\% Cl: - 1.3-8.4, $p$-value 0.15), although confidence intervals crossed the null in the adjusted model. We found no evidence of an association between positive PedsQL psychosocial scores, or higher parental expenditure on physical activity, with the physical activity variables.

Conclusions: Children in this sample were not meeting the recommended 180 min of daily physical activity. The 2-4year-olds were most active on nursery days. There is no evidence of an association between better PedsQL physical scores and higher levels of MVPA. There was no evidence of an association between expenditure on physical activity and time spent physically active. Further examination in larger representative datasets is needed.
\end{abstract}

Keywords: Physical activity, Preschool children, Quality of life, PedsQL, Expenditure, MVPA

\footnotetext{
* Correspondence: laura.tinner@bristol.ac.uk

'Population Health Sciences, Bristol Medical School, University of Bristol,

Canygne Hall, Bristol BS8 2BN, UK

Full list of author information is available at the end of the article
}

(c) The Author(s). 2019 Open Access This article is distributed under the terms of the Creative Commons Attribution 4.0 International License (http://creativecommons.org/licenses/by/4.0/), which permits unrestricted use, distribution, and reproduction in any medium, provided you give appropriate credit to the original author(s) and the source, provide a link to the Creative Commons license, and indicate if changes were made. The Creative Commons Public Domain Dedication waiver (http://creativecommons.org/publicdomain/zero/1.0/) applies to the data made available in this article, unless otherwise stated. 


\section{Background}

Research has highlighted the importance of physical activity in young children, indicating benefits related to physical and psychological health [1]. The UK guidelines for children under 5 years state that children should engage in at least $180 \mathrm{~min}$ of physical activity per day, which includes light physical activity (LPA) and moderate-to-vigorous (MVPA). In 2011, only $10 \%$ of children under 5 met this recommendation and those aged 3-4 years were sedentary for on average 10$11 \mathrm{~h}$ per day [2].

There are no specific guidelines in the UK regarding the amount of MVPA under 5-year olds should engage in. The UK physical activity guidelines are currently being reviewed and will be published in 2019 by the four country Chief Medical Officers, which is expected to be based upon the recommendation that pre-schoolers should progress to 60 mins of daily MVPA by age 5 [3]. The guidelines for children between 6 and 17 years old in England recommends $60 \mathrm{~min}$ in MVPA per day [4], however, a birth cohort study in the UK found only $51 \%$ of primary school children met this recommendation [5]. Establishing behaviours in preschool children may result in increased levels of physical activity in later life, as physical activity behaviours track from childhood into adulthood [6]. There is limited and varied evidence of pre-schoolers levels of MVPA, with most of the evidence not gathered in the UK. A study of physical activity in children aged 35 years in the USA found that in childcare, children only spend 3\% of time in MVPA [7]. Whereas a cross-sectional study in Southampton, England found that while 3-4year-olds met the UK physical activity guidelines, the children spent the majority of their time in LPA [8]. There is therefore a need to increase physical activity and MVPA into the daily routines of pre-school children [9].

Childcare usage is high in the UK, with national statistics in 2018 finding that $72 \%$ of 2 -year-olds and $94 \%$ of 3-4year-olds benefited from universal funded early education places [10]. Therefore, nurseries remain an important setting for research on physical activity amongst young children.

A number of qualitative studies have highlighted the potential barriers to children and adolescents being physically active as lack of financial support from parents and lack of transportation [11-14]. Differential access to formal and paid for physical activities such as swimming is also a suggested contributor to inequalities in childhood obesity prevalence $[11,15,16]$. It is therefore important to investigate whether family expenditure on a child being physically active is associated with physical activity in children. However, to our knowledge, no study has measured this association in pre-school age children.

Health-related quality of life (HRQOL) is a multidimensional construct that includes physical, emotional and social health dimensions as delineated by the WHO $[17,18]$.
In children, HRQOL is an important indicator of everyday functioning [19] so there is a rationale that HRQOL may be associated with physical activity [20]. It is important to examine this association, as health promotion strategies could have a dual benefit in improving both physical activity levels and quality of life in children [21].

There is inconsistent evidence on the relationship between physical activity and HRQOL in children. One crosssectional study found an association between HRQOL and physical activity in children and adolescents, with less physically active children tending to have lower quality of life [22]. A cluster randomized control trial, however, found that a physical activity intervention had no effect on HRQOL in preschool aged children in Canada [20]. The authors of the report stated that more research should be undertaken in preschool aged children, given that more physically active children are less likely to have difficulty walking [23], which is one measure of HRQOL.

The current study explores the association between objective accelerometer-measured physical activity with child HRQOL and family expenditure on physically activities. The Pediatric Quality of Life Inventory (PedsQL) [24] is an instrument that measures health-related quality of life in four domains: physical function, emotional function, social function and nursery function. To our knowledge, this present study is unique in comparing physical activity with the Pediatric Quality of Life Inventory (PedsQL) [24] as a measure of quality of life among 2-4-year olds in a UK community setting. We hypothesized that families that spent more on physical activity for their child would have a more active child and that children with higher PedsQL scores would be more physically active. However, the study remains exploratory, given that the trial was a feasibility study.

\section{Methods}

The analyses were performed using baseline data from the Nutrition and Physical Activity Self-Assessment for Child Care UK (NAP SACC UK) feasibility randomized control trial [9]. NAP SACC UK is a nursery based intervention that employs elements of Social Cognitive Theory (SCT) within a socioecological framework [9]. The aim of NAP SACC UK is to improve the nutritional quality of food served, amount of physical activity and childcare settings' policies around nutrition and physical activity. Further details on methods and study design are in the study protocol [9]. Baseline data collection was conducted in September to December 2015. Written informed consent was obtained by all children's parents. Ethical approval for this study was given by Wales 3 NHS Research Ethics Committee.

\section{Participants}

The study participants were recruited from 12 nurseries within two areas of south-west England: North Somerset 
and Gloucestershire. Children recruited were 2-4 years old and attended nurseries for at least $12 \mathrm{~h}$ per week.

\section{Description of measures}

Study variables included physical activity, quality of life, expenditure on physical activity and demographic information.

Physical activity was measured using ActiGraph GT1M accelerometers which have been shown to provide accurate and reliable assessments of physical activity in children [25]. Accelerometers were worn for 7 days including weekends and days not in nursery. The accelerometers were set to record at $10 \mathrm{~s}$ epochs [26]. To be included in the analysis the participants were required to have 2 days of valid data, either spent at nursery or not. Periods of $\geq 60 \mathrm{~min}$ with zero counts, allowing for 2 min of interruption, were taken as time the accelerometer was not worn and were removed from the analysis [25]. Parents and nursery staff were asked to remove the accelerometers during sleeping, bathing and swimming. A day was considered valid if 8 hours of data were recorded [27]. Data were processed to assess mean minutes of total physical activity (light, moderate and vigorous) and mean minutes of MVPA (moderate and vigorous physical activity). The thresholds for activity intensities were defined using criteria outlined by Puyau [28] as: sedentary $(<800$ counts per minute (cpm)), light (LPA, $800<3200 \mathrm{cpm}$ ) and moderate-to-vigorous (MVPA, $3200<11,715 \mathrm{cpm}$ ) activity. A count value $\geq 11,715 \mathrm{cpm}$ has been deemed "implausible" in previous literature and thus our data were capped at this value [29].

Child's quality of life was measured using The Pediatric Quality of Life Inventory 4.0 (PedsQL) Generic Core Scales questionnaire for children aged 2-4 years [24]. Nursery staff distributed the questionnaires to parents along with a stamped addressed envelope to complete and return to the research team. The instrument has been tested for reliability and validity in community settings [24], including comparing preschool children with and without obesity [30]. The inventory has 21 items rating HRQOL in four domains: physical function, emotional function, social function and nursery function. Parents rated their child's functioning over the past month related to each item on a scale of 0 to $4(0=$ never a problem, $1=$ almost never a problem, $3=$ often a problem, $4=$ almost always a problem). The questionnaire with the PedsQL items can be found in Additional file 1. Items were reverse scored and linearly transformed onto a scale of $0-100$, for ease of interpretation, so that higher PedsQL scores indicated better health-related quality of life. The physical health summary score is calculated as the mean score from the physical function scale ( 8 items). For the psychosocial summary score, the mean was computed as the sum of the items divided by the number of items answered in the emotional, social, and nursery function scales (15 items).

Family expenditure on physical activity of the 2-4year old child was collected from a parent questionnaire. Parents were asked to list all the physical activities their 2-4-year old child had participated in over the past week and the associated cost of each activity (entry fees, membership etc.). A subsequent question asked how many miles in the car were travelled to get to the activity. Expenditure on transport was calculated using the HMRC tax rates per business mile, costed at $45 \mathrm{p}$ per mile [31]. The cost of transport to the activities was added to the expenditure on physical activities to generate the total weekly expenditure on physical activity of the 2-4-year-old.

Demographic information was collected via the parent questionnaire that was distributed by nursery staff. Parents were asked to give their highest educational attainment level, their child's gender and child's date of birth. Date of birth was converted into the child's age and dichotomised into '2 years' and ' $3-4$ years'. The parental education options were: below GCSE/O-levels, up to GCSE/GCEs/O-levels or similar, A-levels/NVQs/GNVQs, first degree/diploma/HNC/ HND, higher degree (e.g. MSc, PhD). GCSE/O-levels are compulsory qualifications taken in schools in England at age 16 years. A-levels/NVQs/GNVQs are optional qualifications taken in England in either sixth forms or further education colleges with A-levels being necessary to be accepted to UK universities. $\mathrm{HNC} / \mathrm{HND}$ are higher education qualifications in the UK and can be equated to a university degree. MSc and $\mathrm{PhD}$ qualifications are post-graduate degrees. This parental education variable was dichotomised for analysis into 'degree' and 'no degree'.

\section{Missing data}

There was a high proportion of missing data in our sample (52\%). A large proportion of accelerometer data was coded as missing as we worked to a threshold that required two full days of physical activity data. Open text questionnaires asking parents about money spent on physical activities additionally suffered from missingness. As this crosssectional analysis uses data from a feasibility study, we did not find it appropriate to perform multiple imputation on exploratory analyses and instead report results from complete case analyses.

Missing PedsQL observations were imputed, as per the PedsQL scoring instructions [32], as there were no participants that had $>50 \%$ of scores missing from any one function scale. 


\section{Statistical analysis}

Medians and inter-quartile ranges of physical activity expenditure, and PedsQL physical and psychosocial scores were presented for gender, age, parental education groups, with null hypotheses of no difference in medians between groups being tested with the Mann-Whitney $U$ test. Means and standard deviations of minutes in physical activity and MVPA were presented for gender, age, parental education, and nursery / non-nursery day groups, with the null hypotheses of no difference in means between groups being tested with the Student t-test. Separate mixed effects linear regression models evaluated the strength of associations between measures of physical activity as the outcome variables (mean minutes in active time and mean minutes in MVPA), and PedsQL scores and the family expenditure on physical activity as covariates. Variation in mean activity between nurseries was accommodated by including nursery as a random effect. We adjusted models for age, gender and parental education as possible confounders. Expenditure on physical activity and the PedsQL psychosocial summary scores were each included as four ordered categories, as both variables were heavily skewed. PedsQL physical functioning scores were analysed in tertiles due to more than $25 \%$ of the sample having the maximum score of 100. Evidence against the null hypothesis of no trend in mean activity measure across ordered categories of parental expenditure and PedsQL was evaluated using the test for trend. All analyses were conducted in Stata Version 14.2 (StataCorp, College Station, Texas, USA, 2015).

\section{Results}

There were 169 children who had consent for data collection at baseline. Figure 1 shows that the final sample that had complete data for all the measures was 81 children. The majority of the children in the complete data sample had a parent with a university degree (74\%). There was $22.2 \%$ of the sample with a parent whose highest educational attainment was A-Levels. There was no statistical difference in parental education between the children included in the sample and those for which we had consent but were not included in the sample.

In this sample, with data collected in the autumn, $88.9 \%$ of children did not meet the recommended $180 \mathrm{~min}$ of daily physical activity. Table 1 presents the means (SD) of minutes in daily physical activity and minutes in daily MVPA. Participating children $(n=81)$ had a mean (SD) of 141.9 (33.1) minutes of daily physical activity and a mean (SD) of 22.2 (9.9) minutes of daily MVPA. Children spent more minutes being physically active on nursery days compared with non-nursery days (146.9 vs. 137.2, $p=$ 0.05). There was no evidence of difference in minutes spent in MVPA on nursery days compared to non-nursery days (22.8 vs. $21.7, p=0.4)$.
Boys were more physically active than girls, spending 149.0 vs. $133.9 \mathrm{~min}$ in daily activity $(p=0.04)$. Boys also spent more time in MVPA than girls (24.5 vs. $19.6 \mathrm{~min}$, $\mathrm{p}=0.05)$. There were also mean differences between the age groups, with older children being more physically active $(p=0.01)$ and spending more time in MVPA $(p=$ 0.005 ) than younger children. There was no evidence of differences for any of the physical activity variables by parental education.

Table 2 presents the baseline medians and interquartile range (IQR) of weekly expenditure on physical activity, PedsQL physical and psychosocial summary scores. The median (IQR) for family expenditure on weekly physical activity of the 2-4-year-old child was $£ 13.37$ (£3.00-16.37). Further, $50.6 \%$ of the sample spent less than $£ 9.00$ weekly on their 2-4-year-old's physical activity, with $17.3 \%$ spending no money on physical activities. PedsQL scores for the sample were skewed. For the physical functioning summary score, the median (IQR) was 93.8 (84.4-100). The psychosocial summary score was lower than the physical score, with a median (IQR) of 86.5 (80.8-92.3). There was no evidence of difference in scores by gender, age or parental education.

Table 3 shows that for physical activity (light, moderate and vigorous) Tertile 3 is associated with 5.2 more minutes of physical activity than the reference group (95\% CI -12.1, 22.4), with confidence intervals crossing the null. The trend test $p$-value showed no evidence for a trend across the physical functioning tertiles $(p=0.58)$.

There no evidence (Table 3 ) of an association between PedsQL physical functioning and mean minutes in daily MVPA. Tertile 2 (scores ranging from 87.5193.75) was associated with 3.3 more minutes in MVPA than the reference group with the lowest physical functioning scores (95\% CI: - 1.5, 8.1). Tertile 3 (scores ranging from 93.76-100) was associated with $3.6 \mathrm{~min}$ more MVPA than the reference group (95\% CI: $-1.3,8.4)$. The trend test $\mathrm{p}$-value $(p=0.18)$ showed no evidence for a trend across the physical functioning tertiles. The unadjusted model (Appendix 1 ) showed very weak evidence for a trend across the physical functioning tertiles $(p=0.06)$, that attenuated after adjusting for confounding variables.

For the PedsQL psychosocial summary score, the regression models for physical activity (Table 3 ) show that Quartile 3 was associated with 14.5 min more active time than the reference group (95\% CI: - 3.2, 32.2). For MVPA, the quartile with the highest PedsQL psychosocial scores (Quartile 4) was associated with 1.2 more minutes in MVPA compared with the reference group (95\% CI: -3.9 , 6.3). Quartile 3, with psychosocial scores ranging from 86.55-92.31, was associated with $5.8 \mathrm{~min}$ more time in MVPA (95\% CI: $-0.8,10.8)$ than the reference group. The trend test $p$-value showed no evidence of a trend across 


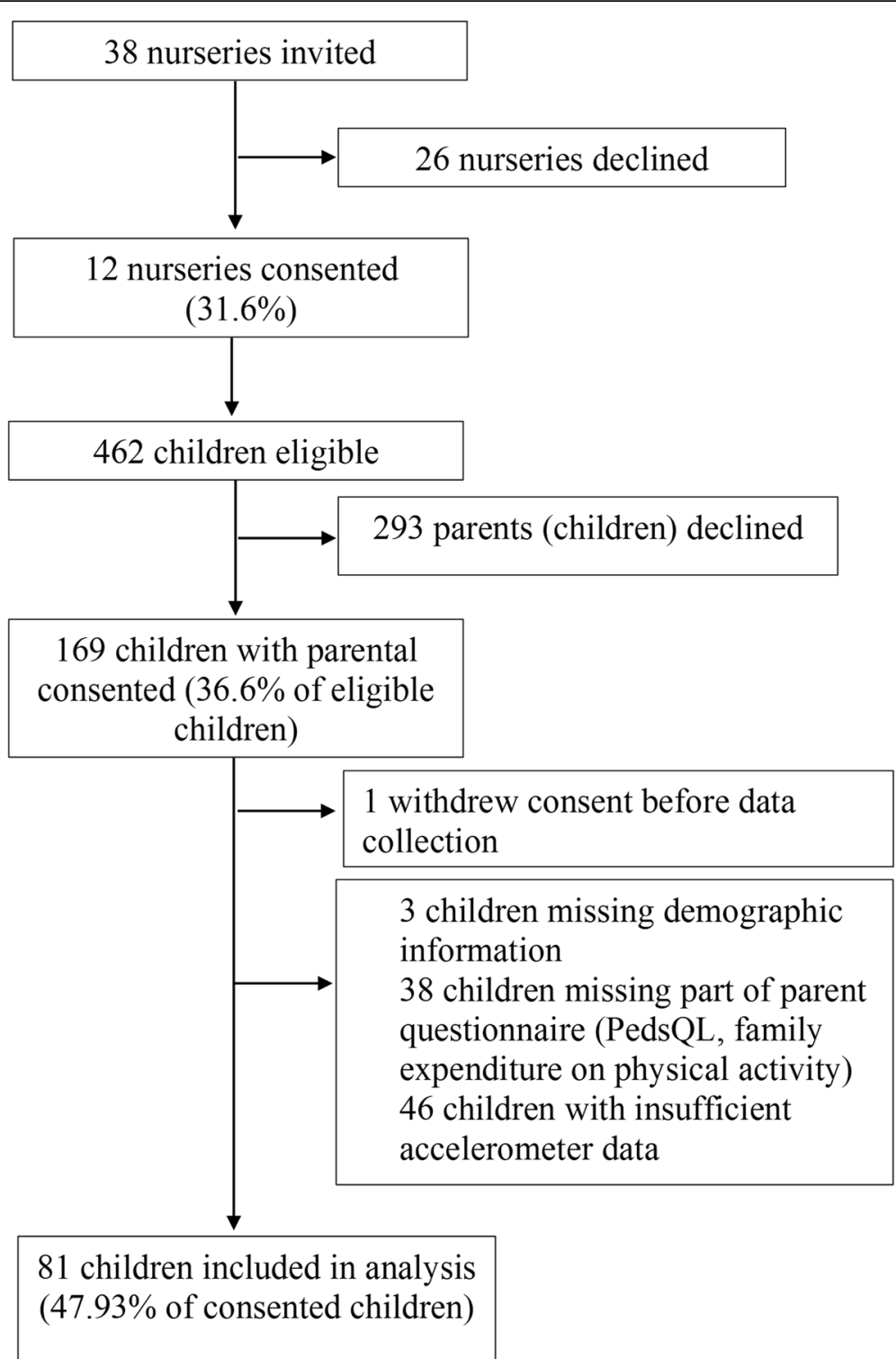

Fig. 1 Flow diagram of participants included in the sample. The diagram shows the derivation of the sample in this study. It shows participants recruited into the NAP SACC UK trial and describes where participants withdrew or there was missing data, resulting in the final sample

the psychosocial quartiles for physical activity $(p=0.88)$ or MVPA $(p=0.32)$.

For the physical activity expenditure variable, the regression model in Table 3 shows no evidence of a relationship between the amount of money spent on the 2-4-year-old being physically active and minutes in daily activity or daily MVPA. However, the differences in mean activity indicate that most quartiles engaged in less physical activity and time in MVPA compared with the reference group, which contains the lowest family expenditure $(£ 0-2.25$ weekly) on the child's physical activity.

\section{Discussion}

This study found that $88.9 \%$ of 2 -4-year-old children are not meeting the recommended $180 \mathrm{~min}$ of daily physical activity. This replicates results from previous studies $[2,4]$. Boys were more physically active than girls, which is consistent with previous studies showing boys engage in more and higher intensity physical activity than girls at preschool age [33-36]. Children aged 3-4 years were more physically active and spent more time in MVPA than children aged 1-2 years, which would be expected due to older children being more developmentally capable of more frequent and higher intensity movement [2]. 
Table 1 Time spent physically active and in MVPA by gender, age, parent education and nursery/non-nursery day

\begin{tabular}{|c|c|c|c|c|}
\hline & \multicolumn{2}{|c|}{ Physical activity (light, moderate and vigorous) (minutes per day) } & \multicolumn{2}{|c|}{$\begin{array}{l}\text { MVPA } \\
\text { (minutes per day) }\end{array}$} \\
\hline & Mean (SD) & $p$-value ${ }^{1}$ & Mean (SD) & $p$-value \\
\hline Whole sample $(n=81)$ & $141.9(33.1)$ & - & $22.2(9.9)$ & - \\
\hline \multicolumn{5}{|l|}{ Gender } \\
\hline Male $(n=43)$ & $148.9(33.5)$ & & $24.50(11.0)$ & \\
\hline Female $(n=38)$ & $133.9(31.3)$ & 0.04 & $19.61(7.7)$ & 0.03 \\
\hline \multicolumn{5}{|l|}{$\mathrm{Age}^{2}$} \\
\hline 2 years old $(n=38)$ & $131.2(31.1)$ & & $18.29(8.1)$ & \\
\hline $3-4$ years old $(n=43)$ & $151.3(32.3)$ & 0.01 & $25.67(10.1)$ & 0.0006 \\
\hline \multicolumn{5}{|l|}{ Parent Education } \\
\hline Degree $(n=59)$ & $140.3(32.1)$ & & $21.65(9.2)$ & \\
\hline No degree $(n=22)$ & $146.2(36.1)$ & 0.48 & $23.70(11.5)$ & 0.41 \\
\hline \multicolumn{5}{|c|}{ Nursery day/non-nursery day $(n=78)^{3}$} \\
\hline Nursery day & $146.9(44.3)$ & & $22.76(13.3)$ & \\
\hline Non-nursery day & $137.2(33.8)$ & 0.05 & $21.67(10.4)$ & 0.40 \\
\hline
\end{tabular}

Children in this sample are more physically active on nursery days than non-nursery days. This study adds to the literature by highlighting low physical activity levels in preschool aged children, supporting the case for health promotion interventions in this age group. It additionally highlights the need to work with parents and carers to promote physical activity outside nursery.

There was no difference in HRQOL by gender, age of child or parental education (Table 2), This finding, however, is not unexpected, as HRQOL differences have been found between obese and overweight preschoolers [22] and migrant and non-migrant preschoolers [18], but there is no evidence of a difference between 2 and 4-year-olds in UK community populations. It may be the case that young children in healthy, community settings a relatively similar in terms of their HRQOL. However, the small sample size means these findings are tentative.

There was no evidence of an association between PedsQL physical functioning (such as walking, running and lifting things) scores and time spent in MVPA (Table 3). There was very weak evidence of an association between these variables in the unadjusted model (Table 4). However, the confidence intervals crossed the null, meaning this finding could be due to chance. Table 3 also shows no evidence of an association between and psychosocial functioning scores and physical activity (light, moderate and vigorous) or MVPA, with no evidence of trend across the quartiles or tertiles. Therefore, the first hypothesis was rejected. Taking the association between psychosocial functioning and physical activity and MVPA as an example, the coefficients for Quartile 2 and Quartile 3 are much greater for physical activity than MVPA (Quartile 2: 10.7 vs 2.2, Quartile 3: 14.5 vs 5.8). Indicatively, this means that PedsQL has a greater effect on light physical activity than on moderate-tovigorous physical activity. Future research with larger samples should interrogate this further, as any observed effect on total physical activity could be mostly attributably to light physical activity. Given the benefits of MVPA, it is important to make this distinction. However, the lack of power in this present study means these findings are only illustrative.

These findings contrast previous research that found associations between physical activity and HRQOL in other age groups [22]. The age of the participants may have impacted upon these results, as HRQOL is reported by the parents on behalf of the child. Previous work has shown parents are able to rate some expects of HRQOL better than others [37]. However, the lack of association between physical activity and HRQOL mirrors Truelove et al's [20] experimental study, which found that a physical activity intervention had no impact on pre-schoolers' PedsQL scores. Further research with larger samples is required to test whether the null finding in our study is due to sample size.

We found no evidence of an association between parental expenditure on physical activities and minutes the child spent in physical activity or MVPA, thus our second 
Table 2 Baseline medians for physical activity and PedsQL scores by gender, age and parent education ${ }^{1}$

\begin{tabular}{|c|c|c|c|c|c|c|}
\hline & \multicolumn{2}{|c|}{$\begin{array}{l}\text { Weekly expenditure on physical } \\
\text { activity for } 1-4 \text { year old }(£)\end{array}$} & \multicolumn{2}{|c|}{$\begin{array}{l}\text { PedsQL Physical Functioning } \\
\text { (scale 0-100) }\end{array}$} & \multicolumn{2}{|c|}{$\begin{array}{l}\text { PedsQL Psychosocial Functioning } \\
\text { (scale 0-100) }\end{array}$} \\
\hline & Median (IQR) & $p$-value ${ }^{2}$ & Median (IQR) & $p$-value ${ }^{2}$ & Median (IQR) & $p$-value ${ }^{2}$ \\
\hline Whole sample $(n=81)$ & $13.4(3.0-16.4)$ & - & $93.8(84.3-100)$ & - & $86.5(80.8-92.3)$ & - \\
\hline \multicolumn{7}{|l|}{ Gender } \\
\hline Male $(n=43)$ & $9.4(0.9-18.4)$ & & $93.8(87.5-100)$ & & $86.5(80.8-94.2)$ & \\
\hline Female $(n=38)$ & $6.4(3.0-14.8)$ & 0.56 & 90.6 (82.3-96.88) & 0.27 & 86.5 (78.9-92.3) & 0.70 \\
\hline \multicolumn{7}{|l|}{ Age } \\
\hline 2 years old $(n=38)$ & $9.0(1.5-16.8)$ & & $92.2(84.4-100)$ & & 86.5 (78.9-92.3) & \\
\hline $3-4$ years old $(n=43)^{3}$ & $7.2(4.5-16.4)$ & 0.62 & $93.8(87.5-100)$ & 0.60 & $88.5(82.7-92.3)$ & 0.27 \\
\hline \multicolumn{7}{|l|}{ Parent Education } \\
\hline Degree $(n=59)$ & $6.8(3.3-15.7)$ & & $93.8(87.5-100)$ & & $88.5(80.8-92.3)$ & \\
\hline No degree $(n=22)$ & $10.0(2.3-17.3)$ & 0.59 & $93.8(81.3-100)$ & 0.85 & $82.7(78.8-90.4)$ & 0.15 \\
\hline
\end{tabular}

${ }^{1}$ Table testing two study hypotheses by fitting mixed-effects linear regression models

${ }^{2} p$-value for the mean difference based on t-test

${ }^{3}$ Ten children aged 4 years

hypothesis was not supported. This null finding is in contrast to previous work that has found cost to be an important barrier to physical activity participation [14]. There are a number of possible reasons for the lack of association in this sample. Firstly, it may be the case that some parents spend more money on physical activities for their child, because their child exhibits low levels of physical activity and so they hope to encourage them to do more. Secondly, for some children there are opportunities for free physical activities, such as playing in the garden or in the park. Therefore, access to such spaces may be a more important factor than actual funds spent on activities. Previous research has found increased proximity between homes and park areas to be associated with higher levels of physical activity in young children [38]. A large proportion of the sample spent nothing on physical activities. Further, the small

Table 3 Mixed-effects regression of physical activity, PedsQL and expenditure on physical activity ( $£$ ) of 2-4-year-old children

\begin{tabular}{|c|c|c|c|c|c|c|c|c|}
\hline \multirow[t]{2}{*}{ Adjusted models ${ }^{1}$} & \multicolumn{4}{|c|}{ Physical activity (Light, moderate and vigorous) } & \multicolumn{4}{|c|}{ MVPA (Moderate and vigorous) } \\
\hline & Coefficient & $95 \% \mathrm{Cl}$ & $p$-value ${ }^{2}$ & Trend test ${ }^{3}$ & Coefficient & $95 \% \mathrm{Cl}$ & $p$-value ${ }^{2}$ & Trend test ${ }^{3}$ \\
\hline \multicolumn{9}{|l|}{ Covariate } \\
\hline \multicolumn{9}{|c|}{ PedsQL Physical Functioning score (scale 0-100) } \\
\hline Reference group: $50.00-87.50$ & - & - & - & & - & - & - & \\
\hline Tertile 2: 87.51-93.75 & 5.1 & $-11.9,22.1$ & 0.56 & & 3.32 & $-1.5,8.1$ & 0.18 & \\
\hline Tertile 3: 93.76-100 & 5.2 & $-12.1,22.4$ & 0.56 & 0.58 & 3.6 & $-1.3,8.4$ & 0.15 & 0.18 \\
\hline \multicolumn{9}{|c|}{ PedsQL Psychosocial Functioning score (scale 0-100) } \\
\hline Reference group: 51.92-80.77 & - & - & - & & - & - & - & \\
\hline Quartile 2: 80.68-86.54 & 10.7 & $-7.1,28.6$ & 0.24 & & 2.2 & $-2.9,7.3$ & 0.40 & \\
\hline Quartile 3: 86.55-92.31 & 14.5 & $-3.2,32.2$ & 0.11 & & 5.8 & $-0.8,10.8$ & 0.02 & \\
\hline Quartile 4: 92.32-100 & -1.5 & $-19.4,16.4$ & 0.87 & 0.88 & 1.2 & $-3.9,6.3$ & 0.48 & 0.32 \\
\hline \multicolumn{9}{|c|}{ Total weekly expenditure on physical activity $(£)^{4}$} \\
\hline Reference group: $0.00-2.25$ & - & - & - & & - & - & - & \\
\hline Quartile 2: 2.26-7.20 & -10.1 & $-29.9,9.7$ & 0.32 & & 0.7 & $-4.9,6.3$ & 0.81 & \\
\hline Quartile 3: 7.21-16.70 & -1.8 & $-21.9,18.1$ & 0.86 & & -0.2 & $-5.8,5.5$ & 0.95 & \\
\hline Quartile 4: 16.71-47.15 & 2.1 & $-17.9,22.1$ & 0.84 & 0.68 & 0.2 & $-5.4,5.9$ & 0.93 & 0.996 \\
\hline
\end{tabular}

${ }^{1}$ Adjusted for parental education, child age, gender and cluster

${ }_{2} p$-values for difference between each tertile/quartile and the reference group

${ }^{3} p$-value for trend test across tertiles or quartiles

${ }^{4}$ Minutes on non-nursery days were used under the assumption that spending on physical activity for the 2-4-year-old would occur on non-nursery days 
sample size as well as the high proportion of parents from high socioeconomic backgrounds, 74\% compared to $40.3 \%$ of adults aged $25-34$ and $33.6 \%$ of adults aged 35-49 in England and Wales [39], could have resulted in the lack of association between physical activity and expenditure on physical activities.

\section{Strengths and limitations}

This study is among the first to employ PedsQL as a quality of life measure in this age group, and the first to our knowledge in the UK to use PedsQL among children in a community setting and assess links with physical activity. The study, does however, have limitations. This study was cross-sectional; thus, it cannot be used to determine causal effects of expenditure and PedsQL scores on physical activity levels. As a feasibility trial, the sample size was small, and we had limited statistical power to test for differences in some outcomes we hypothesized. However, we had power to detect a five-minute difference in MVPA between genders. Issues with the amount of usable days of accelerometer data from the children meant that the sample size was further reduced. The $p$-values testing trend across the categorical variables were also high. A further limitation to the study is that the sample is disproportionately made up of children whose parents are of high socioeconomic status based on their education. Although nurseries were recruited from areas of varying neighbourhood deprivation scores, parents in the sample have relatively high education compared to the general population. These parents are likely to be more affluent and have more disposable income to spend on physical activity. Overall, the sample cannot be said to be representative.

\section{Conclusions}

This exploratory study demonstrates $88.9 \%$ children aged 2-4 years old fail to meet physical activity guidelines. There were higher levels of physical activity on nursery days compared with non-nursery days. Our hypothesis that HRQOL and physical activity are associated in young children was not supported by these data. There appears to be no evidence of an association between money spent on physical activity and levels of physical activity or MVPA. This should be explored further, as the lack of association potentially conflicts with the hypothesis of cost as a barrier to physical activity participation. However, for this more affluent sample, this hypothesis may not be relevant within this context as there are not many high cost activities for young children. Replication in larger, more representative samples is required.

\section{Appendix}

\section{Unadjusted models}

Table 4 Mixed-effects regression of physical activity, PedsQL and expenditure on physical activity ( $£$ ) of 2-4-year-old children

\begin{tabular}{|c|c|c|c|c|c|c|c|c|}
\hline \multirow[t]{2}{*}{ Unadjusted models } & \multicolumn{4}{|c|}{ Physical activity (Light, moderate and vigorous) } & \multicolumn{4}{|c|}{ MVPA (Moderate and vigorous) } \\
\hline & Coefficient & $95 \% \mathrm{Cl}$ & $p$-value ${ }^{1}$ & Trend test $^{2}$ & Coefficient & $95 \% \mathrm{Cl}$ & $p$-value ${ }^{2}$ & Trend test ${ }^{\mathrm{a}}$ \\
\hline \multicolumn{9}{|l|}{ Covariate } \\
\hline \multicolumn{9}{|c|}{ PedsQL Physical Functioning score (scale 0-100) } \\
\hline Reference group: $50.00-87.50$ & - & - & - & & - & - & - & \\
\hline Tertile 2: 87.51-93.75 & 11.0 & $-8.0,28.4$ & 0.27 & & 5.7 & $0.4,11.0$ & 0.04 & \\
\hline Tertile 3: 93.76-100 & 8.8 & $-7.7,25.3$ & 0.29 & 0.29 & 4.5 & $-0.1,9.5$ & 0.06 & 0.06 \\
\hline \multicolumn{9}{|c|}{ PedsQL Psychosocial Functioning score (scale 0-100) } \\
\hline Reference group: 51.92-80.77 & - & - & - & & - & - & - & \\
\hline Quartile 2: 80.68-86.54 & 13.2 & $-6.6,32.9$ & 0.19 & & 3.3 & $-2.6,9.1$ & 0.28 & \\
\hline Quartile 3: 86.55-92.31 & 12.3 & $-6.6,31.3$ & 0.20 & & 5.0 & $-.6,10.7$ & 0.08 & \\
\hline Quartile 4: 92.32-100 & 1.6 & $-18.2,21.3$ & 0.88 & 0.76 & 2.4 & $-3.5,8.2$ & 0.43 & 0.28 \\
\hline \multicolumn{9}{|c|}{ Total weekly expenditure on physical activity $(£)^{3}$} \\
\hline Reference group: $0.00-2.25$ & - & - & - & & - & - & - & \\
\hline Quartile 2: 2.26-7.20 & -12.1 & $-33.2,9.0$ & 0.26 & & 0.3 & $-6.1,6.7$ & 0.94 & \\
\hline Quartile 3: 7.21-16.70 & -6.0 & $-26.6,14.6$ & 0.57 & & -1.0 & $-7.2,5.2$ & 0.75 & \\
\hline Quartile 4: 16.71-47.15 & -0.5 & $-21.8,20.9$ & 0.96 & 0.91 & -0.2 & $-6.6,6.2$ & 0.95 & 0.85 \\
\hline
\end{tabular}

${ }^{1} p$-values for difference between each tertile/quartile and the reference group

${ }^{2} p$-value for trend test across tertiles or quartiles

${ }^{a}$ Minutes on non-nursery days were used under the assumption that spending on physical activity for the 2-4-year-old would occur on non-nursery days 


\section{Additional file}

Additional file 1: PedsQL parent questionnaire. The questionnaire given to parents to complete on behalf of their 2-4-year-old child. Parents gave their child a score of 0-5 based on a series of physical and psychosocial parameters such as walking, running, feeling scared, playing with other children. A score of 0 indicated the child never has problems with the parameter and 5 indicated they always have problems. (DOC $49 \mathrm{~kb}$ )

\section{Abbreviations}

A-level: Advanced Level; Cl: Confidence Interval; CPM: Counts per minute; GCSE: General Certificate of Secondary Education; GNVQ: General National Vocational Qualification; HMRC: Her Majesty's Revenue and Customs; HRQOL: Health Related Quality of Life; IQR: Interquartile range; LPA: Light physical activity; MSc: Master of Science; MVPA: Moderate-vigorous physical activity; N: Number; NAP SACC UK: Nutrition and Physical Activity SelfAssessment for Child Care UK; NHS: National Health Service; NVQ: National Vocational Qualification; O-Level: Ordinary Level; p: Pence; PedsOL: Pediatric Quality of Life Inventory; PhD: Doctor of Philosophy; SD: Standard Deviation; WHO: World Health Organisation

\section{Acknowledgements}

This study is sponsored by the University of Bristol. The authors thank all the nursery staff, health staff and parents that took part in NAP SACC UK.

\section{Authors' contributions}

The study was conceptualised and designed by RK, WH, RJ, LT, JW and CM. LT performed the statistical analyses with guidance from JW, RJ, WH and CM. LT drafted the manuscript and all authors were involved in the interpretation of data critically revising the manuscript and approving the final version. All authors read and approved the final manuscript

\section{Funding}

The NAP SACC UK was funded by the National Institute for Health Research (NIHR) Public Health Research Programme (PHR-12/153/39). LT is a PhD student funded by the Medical Research Council within the Centre for the Development and Evaluation of Complex Public Health Interventions (DECIPHer). RJ is partly funded by National Institute for Health Research (NIHR) Collaboration for Leadership in Applied Health Research and Care West (CLAHRC West) at University Hospitals Bristol NHS Foundation Trust

The NAP SACC UK study was designed and delivered in collaboration with the Bristol Randomised Trials Collaboration (BRTC), a UKCRC Registered Clinical Trials Unit in receipt of National Institute for Health Research CTU support funding. The work was undertaken with the support of The Centre for the Development and Evaluation of Complex Interventions for Public Health Improvement (DECIPHer), a UKCRC Public Health Research Centre of Excellence. Joint funding (MR/KO232331/ 1) from the British Heart Foundation, Cancer Research UK, Economic and Social Research Council, Medical Research Council, the Welsh Government and the Wellcome Trust, under the auspices of the UK Clinical Research Collaboration, is gratefully acknowledged.

None of the funders were involved in the Trial Steering Committee, the data analysis, data interpretation, data collection, or writing of the paper. The views expressed in this publication are those of the authors and not necessarily any of the funding bodies listed here, including the NIHR, MRC and the Department of Health.

\section{Availability of data and materials}

The datasets used and/or analysed during the current study are available from the corresponding author on reasonable request.

\section{Ethics approval and consent to participate}

Ethical approval for this study was given by Wales 3 NHS Research Ethics Committee. Informed consent was received from parents of the children participating in this study by returning a stamped, addressed consent form to the study team.

\section{Consent for publication}

Not applicable.

\section{Competing interests}

The authors declare that they have no competing interests.

\section{Author details}

'Population Health Sciences, Bristol Medical School, University of Bristol, Canygne Hall, Bristol BS8 2BN, UK. ${ }^{2}$ Centre for Trials Research, Cardiff University, Cardiff CF14 4YS, UK. ${ }^{3}$ Centre for Exercise, Nutrition \& Health Sciences, School for Policy Studies, University of Bristol, Bristol BS8 1TZ, UK. ${ }^{4}$ The National Institute for Health Research Collaboration for Leadership in Applied Health Research and Care West (NIHR CLAHRC West) at University Hospitals Bristol NHS Foundation Trust, Bristol, UK.

Received: 30 July 2018 Accepted: 9 June 2019

Published online: 28 June 2019

\section{References}

1. Timmons BW, LeBlanc AG, Carson V, Connor Gorber S, Dillman C, Janssen I, Kho ME, Spence JC, Stearns JA, Tremblay MS. Systematic review of physical activity and health in the early years (aged 0-4 years). Appl Physiol Nutr Metab. 2012;37(4):773-92.

2. Department of Health Physical Activity Health Improvement and Protection, Start Active, Stay Active 2011 Availible from: https://www.gov.uk/ government/uploads/system/uploads/attachment_data/file/216370/dh_ 128210.pdf. [Accessed 08 Aug 2017]

3. University of Bristol, UK physical activity guidelines review: second national consultation. 2019 [Accessed: Availible from: http://www.bristol.ac.uk/sps/ research/projects/current/physical-activity/second-consultation/.

4. Townsend N WK, Williams J, Bhatnagar P, Rayner M, Physical Activity Statistics 2015. 2015 Availible from: https://www.bhf.org.uk/publications/ statistics/physical-activity-statistics-2015. [Accessed 09 Aug 2017]

5. Griffiths LJ, Cortina-Borja M, Sera F, Pouliou T, Geraci M, Rich C, Cole TJ, Law $C$, Joshi $H$, Ness AR. How active are our children? Findings from the millennium cohort study. BMJ Open. 2013;3(8):e002893.

6. Malina RM. Physical activity and fitness: pathways from childhood to adulthood. Am J Hum Biol. 2001;13(2):162-72.

7. Pate RR, Mclver K, Dowda M, Brown WH, Addy C. Directly observed physical activity levels in preschool children. J Sch Health. 2008;78(8):438-44.

8. Hesketh KR, MCMinn AM, Ekelund U, Sharp SJ, Collings PJ, Harvey NC, Godfrey KM, Inskip HM, Cooper C, van Sluijs EMF, et al. Objectively measured physical activity in four-year-old British children: a cross-sectional analysis of activity patterns segmented across the day. Int J Behav Nutri Phys Act. 2014;11(1):1.

9. Kipping R, Jago R, Metcalfe C, White J, Papadaki A, Campbell R, Hollingworth W, Ward D, Wells S, Brockman R. NAP SACC UK: protocol for a feasibility cluster randomised controlled trial in nurseries and at home to increase physical activity and healthy eating in children aged 2-4 years. BMJ Open. 2016:6(4):e010622.

10. Department of Education: Provision for children under 5 years of age in England, January 2018. 2018

11. Hesketh K, Waters E, Green J, Salmon L, Williams J. Healthy eating, activity and obesity prevention: a qualitative study of parent and child perceptions in Australia. Health Promot Int. 2005;20(1):19-26.

12. Beets MW, Cardinal BJ, Alderman BL. Parental social support and the physical activity-related behaviors of youth: a review. Health Educ Behav. 2010;37(5):621-44

13. Pocock M, Trivedi D, Wills W, Bunn F, Magnusson J. Parental perceptions regarding healthy behaviours for preventing overweight and obesity in young children: a systematic review of qualitative studies. Obes Rev. 2010; 11(5):338-53.

14. Brockman R, Jago R, Fox KR, Thompson JL, Cartwright K, Page AS. " Get off the sofa and go and play": family and socioeconomic influences on the physical activity of 10-11 year old children. BMC Public Health. 2009;9(1):253.

15. Giles-Corti B, Macintyre S, Clarkson JP, Pikora T, Donovan RJ. Environmental and lifestyle factors associated with overweight and obesity in Perth, Australia. Am J Health Promot. 2003;18(1):93-102.

16. Macintyre S, Maciver S, Sooman A. Area, class and health: should we be focusing on places or people? J Soc Policy. 1993;22(2):213-34.

17. Organization WH: Constitution of the world health organization. 1995.

18. Puder J, Pinto AM, Bonvin A, Bodenman P, Munsch S, Kriemler S, MarquesVidal P. Health-related quality of life in migrant preschool children. BMC Public Health. 2013;13(1):384

19. Coker TR, Elliott MN, Wallander UL, Cuccaro P, Grunbaum JA, Corona R, Saunders AE, Schuster MA. Association of family stressful life-change events 
and health-related quality of life in fifth-grade children. Arch Pediatr Adolesc Med. 2011;165(4):354-9.

20. Truelove S, Johnson AM, Vanderloo LM, Driediger M, Burke SM, Irwin JD, Timmons BW, Gaston A, Tucker P. Preschoolers' health-related quality of life following the implementation of a childcare physical activity intervention. Appl Physiol Nutr Metab. 2017;43(5):453-9.

21. Chen X, Sekine M, Hamanishi S, Wang H, Gaina A, Yamagami T, Kagamimori S. Lifestyles and health-related quality of life in Japanese school children: a cross-sectional study. Prev Med. 2005;40(6):668-78.

22. Shoup JA, Gattshall M, Dandamudi P, Estabrooks P. Physical activity, quality of life, and weight status in overweight children. Qual Life Res. 2008;17(3):407-12.

23. Gopinath B, Hardy LL, Baur LA, Burlutsky G, Mitchell P. Physical activity and sedentary behaviors and health-related quality of life in adolescents. Pediatrics. 2012;130(1):e167-74 peds. 2011-3637.

24. Varni JW, Seid M, Kurtin PS. PedsQL ${ }^{\mathrm{TM}}$ 4.0: reliability and validity of the pediatric quality of life inventory ${ }^{\mathrm{TM}}$ version 4.0 generic Core scales in healthy and patient populations. Med Care. 2001;39(8):800-12.

25. Troiano RP, Berrigan D, Dodd KW, Mâsse LC, Tilert T, McDowell M. Physical activity in the United States measured by accelerometer. Med Sci Sports Exerc. 2008:40(1):181.

26. Er V, Dias Kl, Papadaki A, White J, Wells S, Ward DS, Metcalfe C, Jago R, Kipping R. Association of diet in nurseries and physical activity with zBMI in 2-4-year olds in England: a cross-sectional study. BMC Public Health. 2018; 18(1):1262.

27. Konstabel K, Veidebaum T, Verbestel V, Moreno LA, Bammann K, Tornaritis M, Eiben G, Molnár D, Siani A, Sprengeler O. Objectively measured physical activity in European children: the IDEFICS study. Int J Obes. 2014;38(S2):S135.

28. Puyau MR, Adolph AL, Vohra FA, Butte NF. Validation and calibration of physical activity monitors in children. Obesity. 2002;10(3):150-7.

29. Rich C, Geraci M, Griffiths L, Sera F, Dezateux C, Cortina-Borja M. Quality control methods in accelerometer data processing: identifying extreme counts. PLoS One. 2014;9(1):e85134

30. Kuhl ES, Rausch JR, Varni JW, Stark LJ. Impaired health-related quality of life in preschoolers with obesity. J Pediatr Psychol. 2012;37(10):1148-56.

31. HMRC, Expenses and benefits: business travel mileage for employees' own vehicles. Availible from: www.gov.uk/expenses-and-benefits-business-travelmileage/rules-for-tax. [Accessed 15 Aug 17]

32. Varni JW, Scaling and Scoring of the Pediatric Quality of Life Inventory ${ }^{\text {TM }}$ PedsQL. 2017 Availible from: http://www.pedsql.org/PedsQL-Scoring.pdf. [Accessed 15 Aug 2017]

33. Ishii K, Shibata A, Adachi M, Nonoue K, Oka K. Gender and grade differences in objectively measured physical activity and sedentary behavior patterns among Japanese children and adolescents: a cross-sectional study. BMC Public Health. 2015:15(1):1254.

34. Finn K, Johannsen N, Specker B. Factors associated with physical activity in preschool children. J Pediatr. 2002;140(1):81-5.

35. DiPietro JA. Rough and tumble play: a function of gender. Dev Psychol. 1981;17(1):50.

36. Hoffmann ML, Powlishta KK. Gender segregation in childhood: a test of the interaction style theory. J Genet Psychol. 2001:162(3):298-313.

37. Eiser C, Mohay H, Morse RJ. The measurement of quality of life in young children. Child Care Health Dev. 2000;26(5):401-14.

38. Roemmich JN, Epstein LH, Raja S, Yin L, Robinson J, Winiewicz D. Association of access to parks and recreational facilities with the physical activity of young children. Prev Med. 2006;43(6):437-41.

39. Office for National Statistics, Local Area Analysis of Qualifications Across England and Wales. 2014 Availible from: http://webarchive.nationalarchives. gov.uk/20160106225223/http://www.ons.gov.uk/ons/dcp171776_355401.pdf. [Accessed 09 Aug 2017]

\section{Publisher's Note}

Springer Nature remains neutral with regard to jurisdictional claims in published maps and institutional affiliations.

Ready to submit your research? Choose BMC and benefit from:

- fast, convenient online submission

- thorough peer review by experienced researchers in your field

- rapid publication on acceptance

- support for research data, including large and complex data types

- gold Open Access which fosters wider collaboration and increased citations

- maximum visibility for your research: over $100 \mathrm{M}$ website views per year

At $\mathrm{BMC}$, research is always in progress.

Learn more biomedcentral.com/submissions 